\title{
Article
}

\section{The Association between Bone Mineral Density and Periodontal Disease in Middle-Aged Adults}

\author{
Hsin-Hua Chou ${ }^{1,2}$, Sao-Lun Lu ${ }^{3}$, Sen-Te Wang ${ }^{4,5} \mathbb{D}$, Ting-Hsuan Huang ${ }^{3}$ and Sam Li-Sheng Chen ${ }^{1, * \mathbb{D}}$ \\ 1 School of Oral Hygiene, College of Oral Medicine, Taipei Medical University, Taipei 11031, Taiwan; \\ hhchou@tmu.edu.tw \\ 2 Dental Department of Wan-Fang Hospital, Taipei Medical University, Taipei 11600, Taiwan \\ 3 School of Dentistry, College of Oral Medicine, Taipei Medical University, Taipei 11031, Taiwan; \\ ddaniellu@hotmail.com (S.-L.L.); u9718301@cmu.edu.tw (T.-H.H.) \\ 4 Department of Family Medicine, School of Medicine, College of Medicine, Taipei Medical University, Taipei \\ 11031, Taiwan; wangader@gmail.com \\ 5 Department of Family Medicine, Taipei Medical University Hospital, Taipei 11031, Taiwan \\ * Correspondence: samchen@tmu.edu.tw; Tel.: +886-2-2736-1661 (ext. 5211)
}

Citation: Chou, H.-H.; Lu, S.-L.;

Wang, S.-T.; Huang, T.-H.;

Chen, S.L.-S. The Association between Bone Mineral Density and Periodontal Disease in Middle-Aged Adults. Int. J. Environ. Res. Public Health 2021, 18, 3321. https:// doi.org/10.3390/ijerph18063321

Academic Editor: Paul B. Tchounwou

Received: 25 February 2021

Accepted: 19 March 2021

Published: 23 March 2021

Publisher's Note: MDPI stays neutral with regard to jurisdictional claims in published maps and institutional affiliations.

Copyright: (c) 2021 by the authors. Licensee MDPI, Basel, Switzerland. This article is an open access article distributed under the terms and conditions of the Creative Commons Attribution (CC BY) license (https:/ / creativecommons.org/licenses/by/ $4.0 /)$.

\begin{abstract}
The association between osteoporosis and periodontal disease (PD) has been revealed by previous studies, but there have been few studies on the association in younger adults. We enrolled a total of 7298 adults aged 40 to 44 who underwent PD screening between 2003 and 2008. Data on quantitative ultrasound for the measurement of bone mineral density (BMD) were collected for the diagnostic criteria of osteopenia and osteoporosis. The Community Periodontal Index (CPI) was measured for defining PD. A multiple logistic regression model was used to assess the effect of low bone mass on the risk of PD. Of 7298 enrollees, $31 \%$ had periodontal pockets $>3 \mathrm{~mm}, 36.2 \%$ had osteopenia, and $2.1 \%$ had osteoporosis. The $39.8 \%$ of PD prevalence was high in adults with osteoporosis, followed by $33.3 \%$ in osteopenia. A negative association was found between BMD and CPI value $(p<0.0001)$. Low bone mass was associated with the risk of PD (adjusted OR: 1.13; 95\% CI:1.02-1.26) after adjusting the confounding factors, including age, gender, education level, overweight, smoking status, past history of osteoporosis, and diabetes mellitus. An association between BMD and PD among young adults was found. An intervention program for the prevention of PD and osteoporosis could be considered starting in young adults.
\end{abstract}

Keywords: bone mineral density; periodontal disease; osteoporosis; risk factor

\section{Introduction}

Osteoporosis is a systemic skeletal condition characterized by low bone density and the deteriorated microarchitecture of bone tissue, and is mainly seen in the elderly population. It is more common in women than in men. This condition is caused by physiologic agerelated bone loss occurring after menopause. More than one third of the female population aged over 65 suffers from signs and symptoms of osteoporotic fractures [1,2].

Osteoporosis is common in the elderly and there is a relatively low prevalence of osteoporosis in young adults [3]. Wowern et al. revealed that severe osteoporosis which significantly reduces the bone mineral content of the jaws may be associated with a less favorable attachment level in the case of periodontal disease (PD) [4]. Since the loss of alveolar bone is a prominent feature of PD, severe osteoporosis is suspected of being an aggravating factor in the case of PD.

The Global Burden of Disease Study reported that severe PD was the 11th most prevalent condition in the world in 2016 [5,6]. The prevalence of PD was reported to be between $20 \%$ and $50 \%$ globally [7]. The overall periodontitis prevalence has shown to increase with age, and the incidence rises sharply in adults aged 30-40 years [8].

To our knowledge, the relationship between osteoporosis and PD in young adults is rarely addressed and difficult to establish due to the association being confounded by other 
factors such as gender, hormone intake, smoking, race, and age [9]. Furthermore, previous studies have assessed osteoporosis from changes in the metacarpal index [10,11], which may not give a correct estimate of the bone mineral content of the jaws.

In Taiwan, population-based PD screening has been conducted since 2003 among residents aged 35-44 years, in which information on both demographic and chronic disease has been documented [12]. This would enable us to investigate osteoporosis and PD among young adults with other confounding factors.

We therefore aim to investigate the association between osteoporosis and periodontal disease in the context of the current periodontal etiology model in young adults based on data from a large population-based periodontal disease screening.

\section{Materials and Methods}

\subsection{Setting and Study Population}

A population-based cross-sectional study design was adopted, with a total of 15,537 subjects aged 35-44 years from between 2003 and 2008 being recruited from the Keelung community-based integrated screening program (CIS), Taiwan. Briefly, CIS is an integrated disease screening program for adults aged over 30 years old from Keelung City, Taiwan. The main screening items consist of cancers (oral, breast, liver, cervical, and colorectal cancer) and chronical diseases (hypertension, hyperglycemia, and hyperlipidemia) in light of evidence-based medicine. The assessment of PD for individuals aged 35-44 years has been incorporated into the program since 2003.The details of CIS with PD screening have been described in detail elsewhere [12]. This study was approved by the Joint Institutional Review Board of Taipei Medical University (TMU-JIRB No.201207011).

\subsection{Periodontal Survey Procedures}

The periodontal examination by the Community Periodontal Index (CPI) (WHO, 1997) has been used to identify the status of PD. The examiner used a WHO probe to obtain five levels of ordinal scores (healthy, gingival bleeding, calculus, shallow pockets of $4-5 \mathrm{~mm}$, and deep pockets of $6 \mathrm{~mm}$ or deeper). CPI scores by six sextants including two anterior sextants and four posterior sextants for each individual were collected in this study. To be efficient for the large scale survey in the community, WHO suggests the examination for index teeth (1-2 teeth) from each sextant to represent the periodontal status of that sextant. The highest CPI score among the six sextants was adopted to represent the periodontal status for each individual [13].

\subsection{Questionnaire Survey}

The structured questionnaire contained items on (1) lifestyle, with details of cigarette smoking, alcohol consumption, and betel-quid chewing, as well as the associated frequency of consumption and duration of habits; (2) personal disease history of osteoporosis, diabetes mellitus, hypertension, CVD, and cerebrovascular disease. The questionnaire was administered by public health nurses in the CIS program.

\subsection{The Measurement of Metabolic Syndrome (MetS)}

MetS was defined according to the joint scientific statement criteria [14], which requires the presence of 3 or more of the following criteria: (1) elevated fasting glucose value ( $\geq 100 \mathrm{mg} / \mathrm{dL}$ ); (2) elevated BP (systolic pressure $\geq 130$ or diastolic pressure $\geq 85 \mathrm{~mm} \mathrm{Hg}$ ); (3) reduced HDL cholesterol level ( $<40 \mathrm{mg} / \mathrm{dl}$ in men or $<50 \mathrm{mg} / \mathrm{dL}$ in women); (4) elevated triglyceride level ( $\geq 150 \mathrm{mg} / \mathrm{dL})$; and (5) elevated waist circumference ( $\geq 90 \mathrm{~cm}$ in men or $\geq 80 \mathrm{~cm}$ in women). 


\subsection{The Measurement of Bone Mineral Density}

The quantitative ultrasound measurements were performed at one calcaneus for each participant aged over 40 by well-trained technicians to determine the individuals' bone mass. T-score was recorded after quantitative ultrasound assessment. Bone mineral density (BMD) values are expressed as absolute values in $\mathrm{g} / \mathrm{cm}^{2}$ or as T-scores from the young adults. In the current analysis, osteopenia was defined as a T-score between -1.0 and -2.5 , while osteoporosis was defined as a T-score $<-2.5$, as recommended by the World Health Organization guidelines [15].

\subsection{Statistical Analyses}

The participants aged between 40 and 44 years attending both BMD measurement and periodontal disease screening programs were recruited in our analysis. A total of 7298 samples with complete BMD information were used to estimate the severity of PD. The dependent variable in our study was PD. Subjects with CPI scores over 3 was defined as PD. Four sets of variables were tested collectively against PD in multivariate logistic regression modeling: (1) osteoporosis defined by BMD, (2) demographic and behavioral variables commonly included in interview-based surveys (including age, gender, past history of osteoporosis, smoking, betel-quit chewing, and alcohol consumption), (3) overweight (a BMI greater than or equal to 25) by the WHO's definition, and (4) variables addressing the metabolic syndrome status. The statistical significance level was set at $5 \%$. The ANOVA test was used to test the differences between CPI score and BMD value. The significant risk factors were selected in a multivariate logistic regression model based on the stepwise method. All the analyses were performed with the SAS statistical software, version 9.4 (SAS institute, Inc., Cary, NC, USA).

\section{Results}

Among the 7298 subjects, the overall prevalence of PD (CPI $\geq 3$ ) was $31 \%$. The prevalence of PD increased with age from $27.5 \%$ for age 40 years to $33.9 \%$ for age 44 years (Table 1). The prevalence of PD was $37.9 \%$ higher in males than in females $(27.5 \%)$. The prevalence of PD increased with education levels from high (26.9\%) to low (35.1\%). PD prevalence was highest in subjects with osteoporosis (39.9\%), followed by subjects with osteopenia (33.3\%), compared to those without low bone mass $(29.5 \%)$. The prevalence of osteoporosis (BMD $\leq-2.5)$ was $2.1 \%$ (153/7298). The prevalence of osteopenia $(-2.5<$ BMD $\leq-1)$ was $36.2 \%(2644 / 7298)$.

The distribution of BMD by CPI score is presented in Table 2. The higher the CPI value was, the more negative the mean value of BMD was. These differences were statistically significant $(p<0.0001)$ when examined using ANOVA. The risk factors in association with the risk of PD are shown in Table 3. In the univariate analysis, the presence of low BMD (BMD $<-1$, osteopenia or osteoporosis) was associated with an increase in the risk of developing PD of 21\% (OR: 1.21, 95\% CI: 1.10-1.34). Other significant risk factors included age, male, low education level, smoker, past history of osteoporosis, overweight, diabetes mellitus, and metabolic syndrome.

After controlling for these significant confounding factors, low bone mass (BMD $<-1)$ was still associated with the risk of PD (adjusted odds ratio (aOR) $=1.13,95 \%$ CI: 1.02-1.26). 
Table 1. Baseline characteristics of study subjects.

\begin{tabular}{|c|c|c|c|c|c|c|}
\hline Variables & $\mathrm{CPI}<3$ & $\%$ & $\mathrm{CPI} \geq 3$ & $\%$ & Total & $p$ \\
\hline Age & & & & & & \multirow[t]{6}{*}{$<0.0001$} \\
\hline 40 & 926 & 72.5 & 351 & 27.5 & 1277 & \\
\hline 41 & 1033 & 72.4 & 393 & 27.6 & 1426 & \\
\hline 42 & 1037 & 67.8 & 492 & 32.2 & 1529 & \\
\hline 43 & 1005 & 66.4 & 508 & 33.6 & 1513 & \\
\hline 44 & 1026 & 66.1 & 527 & 33.9 & 1553 & \\
\hline Gender & & & & & & \multirow{3}{*}{$<0.0001$} \\
\hline Female & 3439 & 72.5 & 1303 & 27.5 & 4742 & \\
\hline Male & 1588 & 62.1 & 968 & 37.9 & 2556 & \\
\hline Education level & & & & & & \multirow{4}{*}{$<0.0001$} \\
\hline Junior high school or below & 1484 & 73.1 & 546 & 26.9 & 2030 & \\
\hline Senior high school & 2428 & 68.2 & 1130 & 31.8 & 3558 & \\
\hline College or above & 1089 & 64.9 & 589 & 35.1 & 1678 & \\
\hline Bone Mineral Density (BMD) & & & & & & \multirow[t]{3}{*}{0.0002} \\
\hline $\mathrm{BMD}>-1$ & 3172 & 70.5 & 1329 & 29.5 & 4501 & \\
\hline $\begin{array}{c}-2.5<\text { BMD } \leq-1 \\
\text { (osteopenia) }\end{array}$ & 1763 & 66.7 & 881 & 33.3 & 2644 & \\
\hline $\mathrm{BMD} \leq-2.5$ (osteoporosis) & 92 & 60.1 & 61 & 39.9 & 153 & \\
\hline Past History of Osteoposis & & & & & & \multirow{3}{*}{0.0089} \\
\hline No & 4757 & 68.6 & 2180 & 31.4 & 6977 & \\
\hline Yes, without medications & 172 & 71.7 & 68 & 28.3 & 240 & \\
\hline $\begin{array}{l}\text { Yes, with medications } \\
\text { BMI }\end{array}$ & 98 & 81.0 & 23 & 19.0 & 121 & \multirow{3}{*}{$<0.0001$} \\
\hline $18 \leq \mathrm{BMI}<25$ & 4118 & 70.0 & 1767 & 30.0 & 5885 & \\
\hline$\overline{\mathrm{BMI}} \geq 25$ & 887 & 63.8 & 503 & 36.2 & 1390 & \\
\hline Smoking & & & & & & \multirow{2}{*}{$<0.0001$} \\
\hline No & 3652 & 72.2 & 1406 & 27.8 & 5058 & \\
\hline Yes. & 1283 & 60.4 & 841 & 39.6 & 2124 & \\
\hline Alcohol Drinking & & & & & & \multirow{2}{*}{$<0.0001$} \\
\hline No & $\begin{array}{l}3 / 47 \\
1162\end{array}$ & 62.1 & $\begin{array}{l}1525 \\
709\end{array}$ & $\begin{array}{l}28.9 \\
37.9\end{array}$ & $\begin{array}{l}5272 \\
1871\end{array}$ & \\
\hline Betel-quid Chewing & & & & & & \multirow{6}{*}{$\begin{array}{l}<0.0001 \\
<0.0001\end{array}$} \\
\hline No & 4570 & 70.1 & 1854 & 29.9 & 6524 & \\
\hline Yes & 347 & 54.8 & 286 & 45.2 & 633 & \\
\hline Diabetes Mellitus & & & & & & \\
\hline No & 4883 & 69.4 & 2157 & 30.6 & 7040 & \\
\hline Yes & 132 & 55.2 & 107 & 44.8 & 239 & \\
\hline \multicolumn{7}{|l|}{$\begin{array}{c}\text { Component of Metabolic } \\
\text { Syndrome }\end{array}$} \\
\hline Central Obesity & & & & & & \multirow[t]{3}{*}{$<0.0001$} \\
\hline No & 3992 & 70.7 & 1654 & 29.3 & 5646 & \\
\hline Yes & 1035 & 62.6 & 617 & 37.4 & 1652 & \\
\hline Hypertriglyceridemia & & & & & & \multirow[t]{2}{*}{$<0.0001$} \\
\hline No & 3859 & 70.3 & 1630 & 29.7 & 5489 & \\
\hline Yes & 1168 & 64.6 & 641 & 35.4 & 1809 & \multirow{4}{*}{$<0.0001$} \\
\hline Low HDL-C & & & & & & \\
\hline No & 3692 & 70.8 & 1335 & 29.2 & 5214 & \\
\hline Yes & 1522 & 64.1 & 749 & 35.9 & 2084 & \\
\hline Elevated Blood Pressure & & & & & & \multirow{3}{*}{0.0029} \\
\hline No & 4178 & 69.6 & 1822 & 30.4 & 6000 & \\
\hline Yes & 849 & 65.4 & 449 & 34.6 & 1298 & \\
\hline Hyperglycemia & & & & & & \multirow[t]{3}{*}{0.0012} \\
\hline No & 4415 & 69.6 & 1932 & 30.4 & 6347 & \\
\hline Yes & 612 & 64.4 & 339 & 35.6 & 951 & \\
\hline Metabolic Syndrome & & & & & & \multirow[t]{3}{*}{$<0.0001$} \\
\hline No & 4270 & 70.4 & 1799 & 29.6 & 6069 & \\
\hline Yes & 757 & 61.6 & 472 & 38.4 & 1229 & \\
\hline
\end{tabular}

Table 2. The distribution of bone mineral density by the community periodontal index.

\begin{tabular}{cccccc}
\hline \multirow{2}{*}{ CPI } & N & \multicolumn{4}{c}{ Bone Mineral Density } \\
\cline { 3 - 6 } & & Mean & SD & Min & Max \\
\hline 0 & 483 & -0.5459 & 0.96 & -3.33 & 6.40 \\
1 & 997 & -0.5635 & 1.02 & -4.90 & 3.40 \\
2 & 3547 & -0.6083 & 1.04 & -5.81 & 4.80 \\
3 & 1845 & -0.7029 & 1.01 & -4.48 & 4.70 \\
4 & 426 & -0.7433 & 1.00 & -3.10 & 3.70 \\
\hline
\end{tabular}


Table 3. The association between low bone mass, other factors, and periodontal disease (PD).

\begin{tabular}{|c|c|c|c|c|}
\hline \multirow{2}{*}{ Variables } & \multicolumn{4}{|c|}{ Periodontal Disease (CPI $\geq 3$ ) } \\
\hline & OR & $95 \% \mathrm{CI}$ & aOR & $95 \%$ CI \\
\hline Age & 1.09 & $1.06-1.13$ & 1.09 & $1.05-1.13$ \\
\hline Male vs. Female & 1.61 & $1.45-1.78$ & 1.39 & $1.21-1.58$ \\
\hline Education Level & & & & \\
\hline $\begin{array}{l}\text { Junior high school or below vs. } \\
\text { College or above }\end{array}$ & 1.27 & $1.13-1.44$ & 1.30 & $1.15-1.48$ \\
\hline $\begin{array}{l}\text { Junior high school or below vs. } \\
\text { College or above }\end{array}$ & 1.48 & $1.29-1.71$ & 1.51 & $1.30-1.76$ \\
\hline $\begin{array}{c}\text { BMD }<-1 \text { vs. BMD } \geq-1 \\
\text { History of Osteoposis }\end{array}$ & 1.21 & $1.10-1.34$ & 1.13 & $1.02-1.26$ \\
\hline $\begin{array}{l}\text { Without medications vs. } \\
\text { non-osteoposis }\end{array}$ & 0.86 & $0.65-1.15$ & 0.86 & $0.64-1.15$ \\
\hline With medications vs. non-osteoposis & 0.51 & $0.32-0.81$ & 0.47 & $0.30-0.74$ \\
\hline Smoking (Yes vs. No) & 1.70 & $1.53-1.89$ & 1.36 & $1.19-1.56$ \\
\hline Alcohol Drinking (Yes vs. No) & 1.50 & $1.34-1.68$ & & \\
\hline Betel-quid Chewing (Yes vs. No) & 1.93 & $1.63-2.27$ & & \\
\hline $\mathrm{BMI} \geq 25$ vs. $18 \leq \mathrm{BMI}<25$ & 1.32 & $1.17-1.49$ & 1.15 & $1.01-1.30$ \\
\hline Diabetes Mellitus & 1.84 & $1.42-2.38$ & 1.62 & $1.24-2.13$ \\
\hline Metabolic Syndrome & 1.48 & $1.30-1.68$ & $1.21 *$ & $1.05-1.41$ \\
\hline
\end{tabular}

\section{Discussion}

Despite the fact that osteoporosis and PD are prevalent among elderly populations, the PD incidence increased dramatically in young adults. In addition, evidence of the association between osteoporosis and PD has not been well documented in young adults. We investigated the association between low bone mass and PD based on a communitybased epidemiological study of PD in Keelung, Taiwan.

We found that there is a significance correlation between BMD and CPI in that the lower the mean BMD, the higher the CPI. The effect of osteopenia or osteoporosis on the PD was further supported by multiple logistic regression analysis. After adjusting for wellknown confounding factors including age, gender, education level, smoking, overweight, and either diabetes or MetS, low bone mass was associated with a $13 \%$ increase in the risk of $\mathrm{PD}(\mathrm{aOR}=1.13 ; 95 \% \mathrm{CI}: 1.02-1.26)$. Our result is consistent with that of the previous cross-sectional studies covering with younger adults, showing that osteoporosis can be considered a risk factor for PD [16,17]. A meta-analysis also reported that subjects with osteoporosis were 2.17 (OR, 2.17; 95\% CI, 1.80-2.61) times more likely to have periodontitis than those who are free of osteoporosis but the analysis included the studies with elder people [18].

The relationship between osteoporosis and PD may be supported by three mechanisms that have been mentioned, comprising systemic to local bone resorptive disease, hormonal impact on bone homeostasis inflammation, and inflammation and bone homeostasis [19].

Aside from the hormonal effect, the systemic to local bone resorptive disease is considered for describing the link between osteoporosis and PD. A robust association between systematic and local osteoporotic changes in the jaw has been reported. Osteoporosis of the alveolar bone may lower the resistance of the periodontium to infectious challenge and may result in a local infection of the periodontium that first invades the cortical bone and results in a dimensional change in the alveolar ridge [20].

However, a non-infectious mechanism was also considered to be a possible mechanism, since the association between alveolar bone resorption and tooth loss has been shown to be stronger than other clinical measurements of PD [21].

Another possible mechanism involves inflammatory cytokines, in that osteoporosis patients have elevated systemic levels of pro-inflammatory cytokines IL-1, IL-6, and TNF- 
$\alpha$ [20]. These cytokines account for osteoclastogenic bone resorption-inducing cytokines and are also involved in the tissue response to PD [22].

Moreover, homeostatic bone remodeling involves "physiologic inflammation" to recruit non-phlogistic macrophages for the clearance of apoptotic bone cells [23,24]. Interestingly pro-resolving lipid mediators (SPMs) have been unveiled as contributors to an active process of inflammation and are involved in bone homeostasis. Therefore, it is encouraging to understand the role of SPMs in bone homeostasis to disentangle the links between osteoporosis, inflammation, and periodontitis [25].

It is inevitable that there are also studies that have shown a lack of association between osteoporosis and PD [20,26]. Moreover, there is a study that demonstrated that patients with periodontal treatment experience an increased risk of osteoporosis [27]. On the other hand, the inverse relationship between past history of treated osteoporosis and periodontal disease was elucidated in our finding. As a result, whether there is causation between the two conditions is still elusive, in terms of whether osteoporosis causes PD or vice versa. More studies are required. However, our study was based on a large community-based data set and targeted young adults. We believe that our result could be used as a warning to raise public awareness about osteoporosis and PD in young adults.

According to Nordin's definition, osteoporosis is present when the concentration of bone lies more than 2 standard deviations below the mean of young normal values of the same sex [28]. The World Health Organization has also defined osteoporosis as a BMD < $2.5 \mathrm{SD}$ below the mean value of peak bone mass in young normal women [15]. Someone might argue that the dichotomizing subjects by BMD threshold values might result in misclassification bias and loss of information. In this study, both of a continuous variable and a dichotomized variable for BMD were used for the statistical analysis. All these analyses lead to a same result, as demonstrated by a current study of osteoporosis and PD.

Several limitations exist in our study. First, the probing depth was used as a dependent variable to represent PD severity in our study. However, probing depth readings probably do not offer a good measurement of PD history [29]. There are also a few uncontrolled studies that have found an inverse relationship, concluding that subjects with higher BMD retain their teeth with deeper probing depths [30]. Second, the analysis excluded treatment information for periodontal disease which might affect the relationship between bone mineral density and periodontal disease. However, as our National Health Insurance system included the comprehensive periodontal treatment project in 2010, the proportion of treatment for periodontal disease by asymptomatic subjects receiving periodontal disease screening during the study period was expected to be very low. Third, there were still other confounder factors which we could not take into account-for example, vitamin D. However, we believe that the effect from this would be minimal because we focused on young adults. Third, as our design is a cross-sectional study, we could not elucidate the causation between osteoporosis and PD.

\section{Conclusions}

In conclusion, based on community data, we demonstrated that low bone mass increased the risk of PD among young adults. An intervention program for the prevention of PD and osteopenia or osteoporosis may be considered for young adults.

Author Contributions: Conceptualization, H.-H.C. and S.L.-S.C.; methodology, H.-H.C. and S.L.-S.C.; formal analysis, S.-L.L., T.-H.H. and S.L.-S.C.; resources, S.-T.W. and S.L.-S.C.; writing-original draft preparation, H.-H.C. and S.-L.L.; writing-review and editing, S.-T.W. and S.L.-S.C.; visualization, S.-L.L. and T.-H.H.; supervision, S.L.-S.C.; project administration, S.L.-S.C.; funding acquisition, S.L.-S.C. All authors have read and agreed to the published version of the manuscript.

Funding: This research was funded by Ministry of Science and Technology (NSC 101-2314-B-038032-MY2).

Institutional Review Board Statement: This study was approved by the Joint Institutional Review Board of Taipei Medical University (TMU-JIRB No. 201207011). 
Informed Consent Statement: Written informed consent has been obtained from all subjects involved in this study.

Data Availability Statement: The data that support the findings of this study are available on request from the corresponding author. The data are not publicly available due to privacy of research participants.

Acknowledgments: This study is one of a series of KCIS studies (KCIS No. 43). The authors would like to acknowledge the contributions and supports of nurses and health service team workers of the Public Health Bureau of Keelung city.

Conflicts of Interest: The authors declare no conflict of interest.

\section{References}

1. Riggs, B.L. Pathogenesis of osteoporosis. Am. J. Obstet. Gynecol. 1987, 156, 1342-1346. [CrossRef]

2. Melton, L.J.; Chrischilles, E.A.; Cooper, C.; Lane, A.W.; Riggs, B.L. Perspective how many women have osteoporosis? J. Bone Miner. Res. 2009, 7, 1005-1010. [CrossRef]

3. Ferrari, S.; Bianchi, M.L.; Eisman, J.A.; Foldes, A.J.; Adami, S.; Wahl, D.A.; Stepan, J.J.; de Vernejoul, M.-C.; Kaufman, J.-M. Osteoporosis in young adults: Pathophysiology, diagnosis, and management. Osteoporos. Int. 2012, 23, 2735-2748. [CrossRef] [PubMed]

4. von Wowern, N.; Klausen, B.; Kollerup, G. Osteoporosis: A risk factor in periodontal disease. J. Periodontol. 1994, 65, 1134-1138. [CrossRef]

5. Vos, T.; Abajobir, A.A.; Abate, K.H.; Abbafati, C.; Abbas, K.M.; Abd-Allah, F.; Abdulkader, R.S.; Abdulle, A.M.; Abebo, T.A.; Abera, S.F.; et al. Global, regional, and national incidence, prevalence, and years lived with disability for 328 diseases and injuries for 195 countries, 1990-2016: A systematic analysis for the Global Burden of Disease Study 2016. Lancet 2017, 390, 1211-1259. [CrossRef]

6. Nazir, M.; Al-Ansari, A.; Al-Khalifa, K.; Alhareky, M.; Gaffar, B.; Almas, K. Global Prevalence of Periodontal Disease and Lack of Its Surveillance. Sci. World J. 2020. [CrossRef] [PubMed]

7. Sanz, M.; D'Aiuto, F.; Deanfield, J.; Fernandez-Avilés, F. European workshop in periodontal health and cardiovascular diseasescientific evidence on the association between periodontal and cardiovascular diseases: a review of the literature. Eur. Hear. J. Suppl. 2010, 12 (Suppl. B), B3-B12. [CrossRef]

8. Tonetti, M.S.; Jepsen, S.; Jin, L.; Otomo-Corgel, J. Impact of the global burden of periodontal diseases on health, nutrition and wellbeing of mankind: A call for global action. J. Clin. Periodontol. 2017, 44, 456-462. [CrossRef] [PubMed]

9. Genco, R.J.; Löe, H. The role of systemic conditions and disorders in periodontal disease. Periodontol. 2000 1993, 2, 98-116. [CrossRef]

10. Phillips, H.B.; Ashley, F.P. The relationship between periodontal disease and a metacarpal bone index. Br. Dent. J. 1973, 134, 237-239. [CrossRef]

11. Ward, V.J.; Manson, J.D. Alveolar bone loss in periodontal disease and the metacarpal index. J. Periodontol. 1973, 44, 763-769. [CrossRef]

12. Lai, H.; Lo, M.-T.; Wang, P.-E.; Wang, T.-T.; Chen, T.H.-H.; Wu, G.H.-M. A community-based epidemiological study of periodontal disease in Keelung, Taiwan: A model from Keelung community-based integrated screening programme (KCIS No. 18). J. Clin. Periodontol. 2007, 34, 851-859. [CrossRef] [PubMed]

13. Ainamo, J.; Barmes, D.; Beagrie, G.; Cutress, T.; Martin, J.; Sardo-Infirri, J. Development of the World Health Organization (WHO) community periodontal index of treatment needs (CPITN). Int. Dent. J. 1982, 32, 281-91. [PubMed]

14. Alberti, K.G.; Eckel, R.H.; Grundy, S.M.; Zimmet, P.Z.; Cleeman, J.I.; Donato, K.A.; Fruchart, J.-C.; James, W.P.T.; Loria, C.M.; Smith, S.C., Jr.; et al. Harmonizing the metabolic syndrome: A joint interim statement of the International Diabetes Federation Task Force on Epidemiology and Prevention; National Heart, Lung, and Blood Institute; American Heart Association; World Heart Federation; International Atherosclerosis Society; and International Association for the Study of Obesity. Circulation 2009, 120, 1640-1645. [CrossRef] [PubMed]

15. Kanis, J.A. Assessment of fracture risk and its application to screening for postmenopausal osteoporosis: Synopsis of a WHO report. WHO Study Group. Osteoporos. Int. 1994, 4, 368-381. [CrossRef]

16. Kim, J.W.; Kong, K.A.; Kim, H.Y.; Lee, H.S.; Kim, S.J.; Lee, S.H.; Sim, K.W.; Kim, M.R.; Lee, J.H. The association between bone mineral density and periodontitis in Korean adults (KNHANES 2008-2010). Oral Dis. 2013, 20, 609-615. [CrossRef]

17. Inagaki, K.; Kurosu, Y.; Yoshinari, N.; Noguchi, T.; Krall, E.A.; Garcia, R.I. Efficacy of periodontal disease and tooth loss to screen for low bone mineral density in Japanese women. Calcif. Tissue Int. 2005, 77, 9-14. [CrossRef]

18. Xu, S.; Zhang, G.; Guo, J.; Tan, Y. Associations between osteoporosis and risk of periodontitis: A pooled analysis of observational studies. Oral Dis. 2021, 27, 357-369. [CrossRef]

19. Wang, C.-W.; McCauley, L.K. Osteoporosis and Periodontitis. Curr. Osteoporos. Rep. 2016, 14, 284-291. [CrossRef]

20. Kribbs, P.J. Comparison of mandibular bone in normal and osteoporotic women. J. Prosthet. Dent. 1990, 63, 218-222. [CrossRef] 
21. Wactawski-Wende, J. Periodontal diseases and osteoporosis: Association and mechanisms. Ann. Periodontol. 2001, 6, 197-208. [CrossRef] [PubMed]

22. Brincat, S.D.; Borg, M.; Camilleri, G.; Calleja-Agius, J. The role of cytokines in postmenopausal osteoporosis. Minerva Ginecol. 2014, 66, 391-407. [PubMed]

23. Golub, L.; Payne, J.; Reinhardt, R.; Nieman, G. Can Systemic Diseases Co-induce (Not Just Exacerbate) Periodontitis? A Hypothetical "Two-hit" Model. J. Dent. Res. 2006, 85, 102-105. [CrossRef] [PubMed]

24. McCauley, L.K.; Dalli, J.; Koh, A.J.; Chiang, N.; Serhan, C.N. Cutting edge: Parathyroid hormone facilitates macrophage efferocytosis in bone marrow via proresolving mediators resolvin D1 and resolvin D2. J. Immunol. 2014, 193, 26-29. [CrossRef] [PubMed]

25. Sinder, B.P.; Pettit, A.R.; McCauley, L.K. Macrophages: Their Emerging Roles in Bone. J. Bone Miner. Res. 2015, 30, 2140-2149. [CrossRef]

26. Elders, P.J.; Habets, L.L.; Netelenbos, J.C.; van der Linden, L.W.; van der Sieit, P.F. The relation between periodontitis and systemic bone mass in women between 46 and 55 years of age. J. Clin. Periodontol. 1992, 19, 492-496. [CrossRef] [PubMed]

27. Lin, T.-H.; Lung, C.-C.; Su, H.-P.; Huang, J.-Y.; Ko, P.-C.; Jan, S.-R.; Sun, Y.-H.; Nfor, O.N.; Tu, H.-P.; Chang, C.-S.; et al. Association Between Periodontal Disease and Osteoporosis by Gender: A Nationwide Population-Based Cohort Study. Medicine 2015, 94 , e553. [CrossRef] [PubMed]

28. Nordin BEC. The definition and diagnosis of osteoporosis. Salud Pública México 2009, 51, s132-s133. [CrossRef]

29. Theil, E.M.; Heaney, T.G. The validity of periodontal probing as a method of measuring loss of attachment. J. Clin. Periodontol. 1991, 18, 648-653. [CrossRef]

30. Klemetti, E.; Collin, H.L.; Forss, H.; Markkanen, H.; Lassila, V. Mineral status of skeleton and advanced periodontal disease. J. Clin. Periodontol. 1994, 21, 184-188. [CrossRef] 